\title{
CIEENCIA, FILOSOFIA E HUMANIDADES: ONDE FICAM AS CIÊNCIAS SOCIAIS?
}

\author{
Eunice Ribeiro Durham (1)
}

RESUMO: Este trabalho é um comentário ao artigo de Franklin Leopoldo e Silva, publicado no númern anterior desta revista, que trata das relaçס̃es entre ciência e filosofia. O comentário discute a posição das ciências sociais na dicotomia ciência-filosofia, a partir da compreensão do processo de constituição das identidades dos ramos do conhecimento.
ABSTRACT: This is a commentary on an article, by Franklin Leopoldo e Silva, published in a previous number of this journal, concerning the relationship between Phylosophy and Science. The commentary discusses the position of the Social Sciences and the process of establishing scientific identities.

Uma das coisas que os filósofos sabem de longa data, mas os cientistas sociais só aprenderam recentemente, e a duras penas, é que a identidade, individual ou coletiva, só se constrói pela referência a um outro. $O$ interessante desta descoberta é que a elaboração constrastiva da identidade não se reduz a um confronto entre dois sujeitos autônomos, mas se dá através de um complexo jogo de espelhos: cada um estabelece sua identidade através do modo pelo qual imagina que o outro o percebe e percebe a si próprio.

Essa reflexão vem a propósito do artigo de Franklin Leopoldo e Silva, publicado no último número da Revista da USP (2), que é um fascinante exercício do modo pelo qual a identidade da filosofia é construída no espelho de uma imagem da ciência. Sendo a universidade, pela sua própria universalidade, um campo privilegiado para esse jogo, através do qual as diferentes disciplinas demarcam seus espaços próprios, achamos interessante contrastar a visão de ciência elaborada pelo filósofo com aquela, muito diferente, que é produzida pelas ciências sociais (ou, pelo menos, pela antropologia). A diferença das imagens prende-se certamente ao caráter ambíguo das ciências sociais, as quais, na oposição entre ciência e humanidades, sentem-se um pouco no meio do caminho ou melhor, equilibrando-se precariamente com um pé em cada canoa. Daí deve advir a dificuldade que encontramos em aceitar uma oposição entre ciência e humanidades nos termos em que é estabelecida por nosso colega da Filosofia. E

(1) Professora Titular de Antropologia do Departamento de Ciências Sociais da FFLCH-USP

(2) SILVA, F.L. O papel das humanidades no contex to tecnológico. Revista da Universidade de São Paulo. São Paulo, (4): 65-74, Mar. 1987. 
verdade que a antropologia sofre de uma certa ausência de sofisticação conceitual que a coloca numa posição difícil num diálogo com a filosofia. Mas como estamos tratando da construção das identidades, e portanto, de diversas visões de ciência, a contraposição de diferentes perspectivas pode enriquecer a discussão.

No texto do prof. Franklin, a filosofia é definida "no interior das Humanidades, como modalidade cultural que aborda sistemática e criticamente todos os aspectos da experiência humana" (Silva, 1987, p. 66). Apesar da aparente clareza dessa formulação, a relação entre filosofia e humanidades se torna bastante ambígua no decorrer do texto pois, menos que "no interior" a filosofia tende a ser apresentada como estando acima ou no centro desse conjunto. Conjunto, aliás, pouco definido, pois o autor menciona explicitamente as artes, a literatura, a história e, em certo momento, a sociologia. Não ficamos sabendo onde se devem colocar a psicologia, a economia, a geografia, a antropologia e a ciência política, embora, por um conjunto um tanto depreciativo de referências às técnicas de controle social, pudéssemos supor (não fosse a inclusão da sociologia nas humanidades) que estivessem todas incluidas entre as ciências.

A ciência não é propriamente definida, mas aprendemos, no texto, que, para a filosofia, o fundamental é refletir sobre "a articulação entre Ciência e técnica a partir da relação essencial que une estes dois elementos" (Silva, 1987, p. 66). Como não se define também o que seja técnica é necessário entender seu significado a partir do contexto. Num primeiro momento, vamos analisar a prooosição tomando o termo técnica no seu sentido corrente, associado à tecnologia, identificando portanto o termo ciência como se referindo, basicamente, àqueles ramos do conhecimento denominados, no senso comum, como ciências da natureza.

A relação entre ciência e técnica aparece como fundamental, pois é "a técnica, um prolongamento da Ciência que realiza a vocação originária do saber como instrumento de dominação" (Silva, 1987. p. 66). O uso da palavra dominação já dá a entender que há alguma coisa bastante perversa embutida na própria ciência. Essa suspeita se confirma no final do parágrafo, onde lemos que a tarefa que a filosofia se propõe é "indagar por que o homem acredita que a realização de seu destino histórico estaria estreitamente ligada à consumação da supremacia tecnológica sobre a natureza e à instauração de condições técnicas de controle social" (Silva, 1987, p. 66).

Vê-se portanto, claramente, que já há uma postura política implícita nas definições iniciais, que incorpora valores do presente na análise que vai ser feita. Mas sobre essa relação entre presente e passa- 
do voltaremos mais tarde. Queremos partir de outra questão, apresentando a perspectiva da antropologia. De início, parece haver uma identificação total da antropologia com a filosofia, pois muitos antropólogos definem sua disciplina exatamente nos mesmos termos em que o prof. Franklin define a dele. Mas as divergências já aparecem em relação a toda a concepção relativa à técnica, enquanto domínio sobre a natureza.

Em termos da antropologia, essa prevenção inicial em relação à técnica faz muito pouco sentido. Talvez por uma influência excessiva de Lévi-Strauss e de uma familiaridade indevida com Giannotti, parece-nos muito difícil separar as duas faces da experiência humana: o trabalho e a reflexão. Concebemos o próprio processo de humanização como constituído por uma dupla relação do homem com o mundo, isto é, com a natureza e com os outros homens, mundo esse que o próprio homem constrói. Essa dupla relação envolve uma ação técnica que exige uma mediação simbólica. Desse modo não apenas a ciência no seu sentido restrito, mas o conhecimento, no seu sentido amplo, dificilmente podem ser separados dessa matriz fundamental de um ser que age, criando e transformando o mundo e atribuindo um significado ao seu agir. Nesse contexto, a relação essencial entre ciência e técnica nos parece uma manifestação da indissociabilidade entre trabalho e reflexão.

Talvez não seja correto introduzir, nesta discussão, resultados de pesquisas empíricas, uma vez que, na filosofia, não há "nenhuma instância análoga à base factual que possa dirigir a escolha de teorias em função da compatibilidade com o real, tendo em vista seu conhecimento mais abrangente e aprofundado" (Silva, 1987, p. 70). Mas, como estamos apresentando a perspectiva antropológica, a base factual é inevitável. Para a antropologia, a questão da indissociabilidade originária entre trabalho e reflexão, saber e domínio sobre a natureza, surge na análise do processo evolutivo e é anterior ao aparecimento da espécie Homo sapiens. O processo de hominização, dentro da ordem primata é marcado pelo desenvolvimento da posição ereta, do aumento da capacidade craniana, da redução da face e da arcada dentária e do uso de instrumentos. Os dados permitem inferir que essas modificações físicas estão associadas à fabricação e uso de instrumentos, isto é, a um processo novo de domínio sobre a natureza. Podemos supor também, embora neste caso a base factual seja mais frágil, que esse desenvolvimento envolve, simultaneamente, a linguagem e novas formas de vida social. Como todo esse processo, assim como a domesticação do fogo é anterior ao aparecimento do Homo sapiens, podemos considerar a nossa espécie como um produto da cultura, resultado de uma nova forma de relação com o ambiente (dada pela técnica), sem a qual sequer é possível a sua sobrevivência biológica. 
Para o antropólogo, portanto, instrumentos, linguagem e vida social aparecem como dimensões indissociáveis do mesmo fenômeno.

Mas não se trata apenas disso - se tomarmos o termo técnica no seu sentido mais amplo, e incluirmos na discussão as técnicas de controle social, a mesma postura se mantém. A própria vida social se coloca, para a antropologia, como envolvendo necessariamente, alguma forma de controle. O característico da sociedade humana, na visão antropológica, é a substituição de uma programação geneticamente determinada do comportamento social por uma "regra" (conforme Lévi-Strauss), ou por modelos simbólicos (na colocação de Geertz), construídos pelo homem. De uma forma ou de outra, o problema fundamental é a existência necessária da norma, sem a qual é impossivel pensar a sociedade. A questão do controle, como a da técnica, portanto, estão postas como condic̣ões essenciais da existência da sociedade.

Vê-se então que, a partir de uma tradição diversa, assumimos uma perspectiva diferente daquela que orienta o estudo do prof. Franklin. Isto é, não tomamos a "vocação originária do saber como instrumento de dominação" como perversa, como o texto do prof. Franklin parece dar a entender, pois ela constitui a condição originária fundamental e necessária, do processo de hominização. Tabém não a restringimos à ciência, mas a pensamos como característica de todo processo de conhecimento.

Mas a diferença talvez resida no fato de que o filósofo não esteja realmente examinando o problema a partir da totalidade da experiência humana, tal como os antropólogos a entendem, mas esteja restringindo sua crítica a uma tradição cultural específica - a que se estabelece na nossa civilização a partir do Renascimento, com o desenvolvimento de uma nova racionalidade técnica. Parece ser esse, efetivamente, o momento do pecado original, em que a instauração da razão científica fragmentou o saber e destronou a filosofia de sua posição privilegiada, como lugar de integração de todo conhecimento. Talvez, a partir desse momento, tenha-se instaurado realmente uma relação perversa através da qual o domínio da natureza pela técnica determine, num novo sentido, a dominação do homem pelo homem.

Mesmo dessa perspectiva, no entanto, é difícil para um antropólogo concordar com o filósofo. Acostumados a lidar sempre com uma base factual, ficamos nos perguntando em quê essa nova dominação é assim tão pior do que aquela que caracterizou a Grécia Antiga, na época em que a filosofia incorporava todo o saber, e a liberdade do cidadão se realizava graças ao trabalho do escravo.

Assim, se é verdade que a utilização da ciência para criar novas 
técnicas não libertou o homem, permitiu que, pelo menos, se pensasse pa possibilidade dessa libertação. Os gregos certamente não podiam conceber a universalização da cidadania porque não podiam dispensar o escravo. Essa parece ser também a posição de Marx quando, criticando os socialistas utópicos, afirma que o domínio da natureza é condição essencial para a efetiva libertação do homem -..- isto é, dominando a natureza pela técnica, seria possível não ter mais que escravizar o homem para produzir o substrato material necessário à civilização.

Também não fica muito claro, para um antropólogo, por que a aplicação da mesma racionalização técnica no campo das relações sociais provoca uma forma de dominação mais deletéria que as anteriores. Parece-nos que a religião e filosofia, na Idade Média, serviram tão bem (ou melhor) aos propósitos da dominação do homem pelo homem, quanto a ciência o fez no período posterior. E embora Maquiavel não seja propriamente um antropólogo, um conhecimento talvez um tanto superficial de sua obra nos leva a crer que sua reflexão sobre o poder, como exemplo da utilização da nova razão, revelando as técnicas de controle do homem sobre o homem, tanto pode servir ao príncipe como ao povo.

Essa passagem pelo Renascimento, assim como a menção à Grécia Antiga e à Idade Média, nos permite levantar um outro problema, igualmente fundamental, que é a relação da ciência e da filosofia (das humanidades?) com o passado e com a tradição.

O filósofo atribui à ciência uma concepção linear de tempo, na medida em que a "continuidade progressiva da Ciência não está condicionada à avaliação crítica da tradição, porque na Ciência existe a figura da superação das soluções tradicionais e da resolução de novos problemas" (Silva, 1987. p. 70). Na filosofia, como na literatura e na história, o trabalho de investigação se faria dentro de uma continuidade muito maior com a tradição, pois esta é matéria de pesquisa. "Uma vez que não há propriamente progresso de uma doutrina filosófica para outra, o conhecimento da tradição não pode se guiar por parâmetros seletivos ou por critérios de relevância teórica tomados a partir do presente" Mais ainda, "Não há, nesse caso, nenhuma instância análoga à base factual que possa dirigir uma escolha de teorias em função da compatibilidade com o real" (Silva, 1987, p. 70).

Aqui, mais uma vez, os antropólogos e, provavelmente, também os cientistas políticos não saberiam bem onde se localizar. A antropologia e, mais ainda, a ciência política, pretendem ter com a tradição a relação crítica que a filosofia postula para si, para a história e para a literatura. Assim, a constante referência a Maquiavel, Hobbes e 
Rousseau (por exemplo), que permeia toda a reflexão politica, consiste exatamente nessa constante reincorporação do passado que caracteriza as nossas disciplinas. Do mesmo modo, na antropologia, Morgan, Tylor, Malinowski, não são descartados como portadores de um saber ultrapassado. Mas, por outro lado, não julgamos possível incorporar essa tradição e muito menos fazê-lo criticamente, a não ser guiados por parâmetros seletivos ou por critérios de relevância teórica tomados a partir do presente. Isto é, não acreditamos que seja possível despojar-nos do presente, por mais que o tentemos. $\mathrm{Na}$ antropologia, especificamente, o mesmo problema se coloca em relação a seu próprio objeto, pois o esforço em apreender a experiência de sociedades diferentes da nossa só pode ser feito em termos de um diálogo entre nós e os outros, dentro do qual nossas referências podem ser relativizadas, mas não abolidas. A recuperação do passado parece-nos, portanto, ser sempre uma leitura feita pelo presente e através de parâmetros e critérios de relevância tomados do presente e é por isso que cada autor, em cada época, é capaz de fazer uma leitura nova da tradição, a partir das novas perguntas que o presente constantemente produz. Somos assim guiados por parâmetros seletivos e por critérios de relevância teórica tomados a partir dos problemas que o presente nos coloca (e é isso que faz com que a leitura de Aristóteles por S. Thomás de Aquino não seja exatamente a mesma daquela efetuada hoje). É a aceitação dessa inelutável relação com o presente que permite apreender a dimensão propriamente política (para não falar ideológica) da nossa reflexão e defender, em nome da razão cientifica, a necessidade de explicitar essas referências que orientam a percepção do passado (ou das outras sociedades).

Negar essa relação parece-nos uma forma de ocultar as posições políticas que organizam nossa reflexão. Em nosso entender, é a explicitação dessas referências que constitui a base de uma reflexão crítica.

Dentro dessa perspectiva, uma vez reintroduzido o presente na relação com o passado, reintroduzimos, com ele, a base factual inescapável que é dada pelos problemas a partir dos quais fazemos as indagações - no caso, a fragmentação do saber, as novas formas de dominação, sua relação com o desenvolvimento tecnológico etc.

Colocada a questão dessa forma, a oposição entre ciência e humanidades não se apresenta, para os antropólogos, da forma radical pela qual a concebe nosso colega da Filosofia. $E$ isso porque, embora na ciência exista "a figura da superação das soluções tradicionais e da resolução de novos problemas" (Silva, 1987, p. 70), é o segundo aspecto que nos parece ser o mais fundamental na definição da atividade científica. Dentro deste ponto de vista, o progresso na ciência de- 
fine-se menos pela superação, pura e simples, de teorias anteriores, do que pela construção de novas questões. E são essas novas questões que a filosofia parece incapaz de incorporar. exatamente em virtude do nível de abrangência em que coloca as suas perguntas, que, de fato, são sempre as mesmas. A diferença na temporalidade própria da ciência e da filosofia se desloca, portanto, para outro lugar, em que o caráter cumulativo do conhecimento científico se manifesta na sua capacidade de propor novos problemas e não simplesmente de oferecer novas respostas para as mesmas perguntas. Nessa perspectiva, a antropologia - e, seria o caso de acrescentar, também a ciência política - se identificam com essa imagem de ciência em termos de uma leitura sempre nova, que advém da sua capacidade de propor novas questões.

Talvez pelo fato de mantermos, com o passado e com a base factual, uma relação diferente daquela que parece ser a da filosofia, tenhamos uma imagem também diversa, não só da ciência, mas da forma pela qual imaginamos que os cientistas nos vêem. Ao contrário dos filósofos, nunca nos ocorreu que nossa incorporação permanente das teorias e reflexões produzidas no passado possam nos caracterizar como antiquados, ou que sejamos marginalizados pelos cientistas. Talvez erradamente, sempre imaginamos que os cientistas tivessem o máximo respeito pela nossa competência especifica. Imaginamos até que os cientistas, eles próprios, não possuem de suas disciplinas a visão linear que o filósofo lhes atribui. Mas ainda, julgamos que os problemas colocados pela ciência constituem desafios para a própria reflexão antropológica, pois é indubitável que a ciência moderna alterou radicalmente os parâmetros de nossa concepção do mundo, destroçando as categorias tradicionais de espaço, de tempo e de matéria. Assim, caracterizar a ciência por uma temporalidade linear parece uma simplificação no mínimo questionável.

Aceitando, portanto, o que se poderia chamar de desafio da ciência, nunca nos ocorreu que estivéssemos sendo roubados de nossa identidade. Tivemos, é claro, momentos de crise em que essa identidade parecia se perder - mas sempre atribuímos a crise a uma dificuldade nossa de formular com clareza a natureza de nosso objeto, que deve ser constantemente redefinido e reposto.

Partindo de uma outra tradição e concebendo a ciência de outra forma, vemos também de forma diferente sua relação com a tecnologia e seu lugar na universidade. Admitindo uma indissociabilidade entre trabalho e reflexão, parece-nos fundamental evitar transformar essa relação essencial entre ciência e técnica em uma associação direta entre desenvolvimento científico e aplicação tecnológica. É preciso lembrar que a constituição da universidade moderna, no século $X I X$, 


\section{FICHA CATALOGRÁFICA}

DURHAM, E. R. Ciência, filosofia e humanidades: onde ficam as ciências sociais? Revista da Universidade de São Paulo. São Paulo, (5): 35-43, jun. 1987 